\title{
Modeling the demography of species providing extended parental care: A capture-recapture multievent model with a case study on polar bears (Ursus maritimus)
}

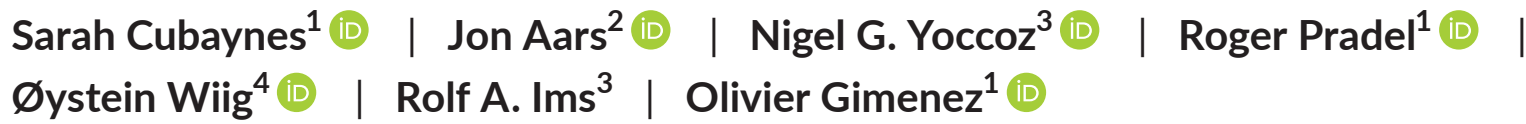

${ }^{1}$ CEFE, Univ Montpellier, CNRS, EPHEPSL University, IRD, Univ Paul Valéry Montpellier 3, Montpellier, France

${ }^{2}$ Norwegian Polar Institute, FRAM Centre, Tromsø, Norway

${ }^{3}$ Department of Arctic and Marine Biology, UiT The Arctic University of Norway,

Tromsø, Norway

${ }^{4}$ Natural History Museum, University of Oslo, Oslo, Norway

\section{Correspondence}

Sarah Cubaynes, CEFE, Univ Montpellier, CNRS, EPHE-PSL University, IRD, Univ Paul Valéry Montpellier 3, Montpellier, France. Email: sarah.cubaynes@ephe.psl.eu

Funding information

Agence Nationale de la Recherche, Grant/ Award Number: ANR-18-CE02-0011; World Wildlife Fund

\section{Abstract}

1. In species providing extended parental care, one or both parents care for altricial young over a period including more than one breeding season. We expect large parental investment and long-term dependency within family units to cause high variability in life trajectories among individuals with complex consequences at the population level. So far, models for estimating demographic parameters in freeranging animal populations mostly ignore extended parental care, thereby limiting our understanding of its consequences on parents and offspring life histories.

2. We designed a capture-recapture multievent model for studying the demography of species providing extended parental care. It handles statistical multiple-year dependency among individual demographic parameters grouped within family units, variable litter size, and uncertainty on the timing at offspring independence. It allows for the evaluation of trade-offs among demographic parameters, the influence of past reproductive history on the caring parent's survival status, breeding probability, and litter size probability, while accounting for imperfect detection of family units. We assess the model performance using simulated data and illustrate its use with a long-term dataset collected on the Svalbard polar bears (Ursus maritimus).

3. Our model performed well in terms of bias and mean square error and in estimating demographic parameters in all simulated scenarios, both when offspring departure probability from the family unit occurred at a constant rate or varied during the field season depending on the date of capture. For the polar bear case study, we provide estimates of adult and dependent offspring survival rates, breeding probability, and litter size probability. Results showed that the outcome of the previous reproduction influenced breeding probability.

4. Overall, our results show the importance of accounting for i) the multiple-year statistical dependency within family units, ii) uncertainty on the timing at offspring independence, and iii) past reproductive history of the caring parent. If ignored, estimates obtained for breeding probability, litter size, and survival can 
be biased. This is of interest in terms of conservation because species providing extended parental care are often long-living mammals vulnerable or threatened with extinction.

\section{KEYWORDS}

apex predator, arctic ecosystem, Bayesian modeling, capture-recapture, dependency among individuals, family structure, parental care, state uncertainty, timing at independence

\section{INTRODUCTION}

Parental care includes any prenatal and postnatal allocation, such as feeding and protecting the young, which benefits the offspring development and survival chances, thereby enhancing the parent's reproductive success (Trivers, 1972). Altricial mammals having offspring that need to learn complex skills to ensure survival beyond independence, such as hunting, orientation, or nest building, show extended parental care (hereafter EPC; Clutton-Brock, 1991). It is defined as a prolonged period, that is, lasting more than one breeding season, over which one or both parents care for one or several dependent young. This period typically lasts for several years and can extend until lifelong maternal care in primates (Van Noordwijk, 2012). For the offspring, the quality and quantity of care received can have long-lasting effects on future survival (e.g., Pavard \& Branger, 2012), social status (e.g., Shenk \& Scelza, 2012), and reproduction (Royle et al., 2012). For the parent, investment in one offspring can compromise its own condition or survival and/or its ability to invest in other offspring (siblings or future offspring) (Stearns, 1992; Williams, 1966). It can indeed take several years during which a parent caring for its offspring will not be available to reproduce, sometimes not until the offspring have reached independence, for example, on average 2.5 years for female polar bears (Ramsay \& Stirling, 1988), 3.5 to 6 years for female African elephants (Lee \& Moss, 1986), and 9.3 years for female Sumatran orangutans (Wich et al., 2004). The fitness costs of losing one offspring, in terms of lost investment and skipped breeding opportunities, are particularly high if death occurs near independence. We therefore expect EPC, through large parental investment and multiple-year dependency among individuals within family units, to cause high variability in life trajectories among individuals and family groups, in interbirth intervals depending on offspring's fate, and consequently on lifetime reproductive success for the caring parent (Clutton-Brock, 1991).

Capture-recapture (CR) models allow studying species with complex demography in the wild, for example, by considering "breeder" and "nonbreeder" reproductive states to estimate breeding probabilities and status-specific demographic parameters while accounting for imperfect detectability (e.g., Lebreton et al., 2009). One can distinguish between successful and failed breeding events (e.g., Lagrange et al., 2017) and include varying litter or clutch size (e.g., Doligez et al., 2002) and memory effects (Cole et al., 2014), to investigate the costs of reproduction on survival and future reproduction for species providing short-term parental care, that is, when offspring reach independence before the next breeding season (e.g., Yoccoz et al., 2002). Indeed, most CR models rely on the assumption of independence among individual CR histories (Lebreton et al., 2009).

In the case of species providing EPC, one challenge stems from the multiple-year dependency among individual's life histories within parent-offspring units. Only few attempts have been made to tackle this issue when estimating demographic parameters, despite the fact that species providing EPC are often among long-living mammals vulnerable or threatened with extinction (e.g., polar bears, orangutans, elephants). Lunn et al. (2016) proposed to model CR histories of mother-offspring units (instead of individuals) to consider the multiple-year dependency of female breeding probability upon offspring survival status for polar bears in Hudson Bay. However, in this model, offspring survival after 9 months is assumed independent of mother survival. Lunn et al. (2016)'s model does therefore not handle multiple-year dependency of offspring survival upon mother survival status, typical of species providing EPC. In addition, because litter size is modeled separately, Lunn et al. (2016)'s model (also used in Regehr et al., 2018) does not permit to explore potential trade-offs among offspring traits and parental phenotypic or demographic traits.

Another challenge involves dealing with uncertain timing at offspring independence, when the offspring departs the caring parent(s) and becomes independent. When studying free-ranging populations, this key life history event is rarely directly observed. When a mature individual is observed without dependent offspring, it is often impossible to know whether its offspring have died or already departed its natal group. As a result, estimates of demographic rates and trade-offs can be underestimated. Based on the analysis of mother-offspring units CR histories, Couet et al. (2019) provided estimates of dolphin reproductive parameters corrected for state uncertainty, but their model assumed a fixed age and timing at offspring independence. Lunn et al. (2016)'s model included variable age at independence, but variability in the timing at offspring independence was not fully dealt with. Demographic rates were corrected by the average annual probability that independence occurred prior to sampling for all offspring, and offspring survival was assumed independent of litter size (Regehr et al., 2018). In most species, timing at offspring independence is variable and could depend on the offspring phenotypic traits (e.g., body size in brown bears, Dahle \& Swenson, 2003), on parental traits (e.g., parent-offspring conflict in kestrels, Vergara 
et al., 2010), social and mating system (e.g., helping behavior in humans, Kramer, 2005), or other environmental determinants (e.g., food supply, Eldegard \& Sonerud, 2010). To our knowledge, no model is available to tackle both the issues of multiple-year dependency among individuals and variable timing at offspring independence. Because of these methodological challenges, the population-level consequences of EPC remain to be understood, especially in free-ranging animal populations.

Here, we develop a CR model specifically for species providing EPC. It is designed to handle multiple-year statistical dependency (until offspring independence) among individual demographic parameters by modeling CR histories grouped within family units. The model accounts for uncertain timing at offspring independence. In addition, our model allows for variability in the number of offspring born and recruited at each breeding event, variable offspring survival depending on number of siblings, and includes the influence of past reproductive history on the caring parent's current status. Finally, estimates of survival rates, breeding probability, and litter size probability are corrected for imperfect detection possibly depending upon family unit composition.

In what follows, we present the model, assess its performance using simulated data, and illustrate its use with a long-term dataset collected on the Svalbard polar bears. Female polar bears rely solely on stored fat reserves during pregnancy and the first three months of lactation, before feeding and protecting litters of one to three young, usually during two more years (Ramsay \& Stirling, 1988). They can lose more than $40 \%$ of body mass while fasting (Atkinson \& Ramsay, 1995). In many areas, climate change and related sea ice decline impact female bear condition and capacity to provide care for their young, with an associated decline in reproductive output (Derocher et al., 2004; Laidre et al., 2020; Stirling \& Derocher, 2012). More insights into the species demography, such as the consequences of long-duration parental care on mother and offspring life histories, could help our understanding of polar bear population responses to environmental perturbations and extinction risks in future decades (Hunter et al., 2010; Regehr et al., 2016).

\section{2 | METHODS}

\section{1 | Capture-recapture model for species providing EPC}

\subsection{1 | Principle}

We develop a CR model in the multievent framework (Pradel, 2005) that is also known as a hidden Markov modeling framework (Gimenez et al., 2012). The principle is to relate the field observations, called events, to the underlying demographic states of interest through the observation process. Uncertainty on state assignment due to variable timing at offspring independence is included in the observation process. In parallel, the state process describes the transition rates
TABLE 1 Definition of the states and events used in the model to describe the polar bear life cycle

\begin{tabular}{|c|c|c|}
\hline Type & Code & Definition \\
\hline \multirow[t]{24}{*}{ States } & $\mathrm{J} 2$ & $\begin{array}{l}2 \text { y.o. independent juvenile } \\
\text { female }\end{array}$ \\
\hline & J3 & $\begin{array}{l}3 \text { y.o. independent juvenile } \\
\text { female }\end{array}$ \\
\hline & SA4 & $\begin{array}{l}4 \text { y.o. independent subadult } \\
\text { female }\end{array}$ \\
\hline & SA5 & $\begin{array}{l}5 \text { y.o. independent subadult } \\
\text { female }\end{array}$ \\
\hline & A01 & $\begin{array}{l}\text { Mother with one dependent cub } \\
\text { of the year }\end{array}$ \\
\hline & $\mathrm{A} 02$ & $\begin{array}{l}\text { Mother with two dependent cubs } \\
\text { of the year }\end{array}$ \\
\hline & A11 & $\begin{array}{l}\text { Mother with one dependent } \\
\text { yearling }\end{array}$ \\
\hline & A12 & $\begin{array}{l}\text { Mother with two dependent } \\
\text { yearlings }\end{array}$ \\
\hline & AS1 & $\begin{array}{l}\text { Successful female breeder with } \\
\text { one two-year-old offspring } \\
\text { reaching independence }\end{array}$ \\
\hline & AS2 & $\begin{array}{l}\text { Successful female breeder with } \\
\text { two two-year-old offspring } \\
\text { reaching independence }\end{array}$ \\
\hline & $A$ & $\begin{array}{l}\text { Adult female without dependent } \\
\text { offspring }\end{array}$ \\
\hline & $\mathrm{D}$ & Dead state \\
\hline & $\mathrm{AO}-$ & $\begin{array}{l}\text { Failed breeder, death of all } \\
\text { offspring cubs of the year }\end{array}$ \\
\hline & A1- & $\begin{array}{l}\text { Failed breeder, death of all } \\
\text { offspring yearlings }\end{array}$ \\
\hline & I/AS1 & $\begin{array}{l}\text { Successful female breeder } \\
\text { alone after departure of one } \\
\text { independent offspring }\end{array}$ \\
\hline & I/AS2 & $\begin{array}{l}\text { Successful female breeder } \\
\text { alone after departure of two } \\
\text { independent offspring }\end{array}$ \\
\hline & $\mathrm{B} / \mathrm{AO}-$ & $\begin{array}{l}\text { Breeder following loss of a cub of } \\
\text { the year litter }\end{array}$ \\
\hline & NB/AO- & $\begin{array}{l}\text { Nonbreeder following loss of a } \\
\text { cub of the year litter }\end{array}$ \\
\hline & B/A1- & $\begin{array}{l}\text { Breeder following loss of a } \\
\text { yearling litter }\end{array}$ \\
\hline & NB/A1- & $\begin{array}{l}\text { Non-breeder following loss of a } \\
\text { yearling litter }\end{array}$ \\
\hline & $\mathrm{B} / \mathrm{AS}$ & $\begin{array}{l}\text { Breeder following successful } \\
\text { reproduction }\end{array}$ \\
\hline & NB/AS & $\begin{array}{l}\text { Non-breeder following successful } \\
\text { reproduction }\end{array}$ \\
\hline & $B / A$ & $\begin{array}{l}\text { Breeder given that previously } \\
\text { without dependent offspring }\end{array}$ \\
\hline & $\mathrm{NB} / \mathrm{A}$ & $\begin{array}{l}\text { Nonbreeder given that previously } \\
\text { without dependent offspring }\end{array}$ \\
\hline
\end{tabular}


TABLE 1 (Continued)

\begin{tabular}{|c|c|c|}
\hline Type & Code & Definition \\
\hline \multirow[t]{12}{*}{ Events } & "1" & $\begin{array}{l}\text { Capture of a } 2 \text { yo independent } \\
\text { female juvenile }\end{array}$ \\
\hline & "2" & $\begin{array}{l}\text { Capture of a } 3 y o \text { independent } \\
\text { female juvenile }\end{array}$ \\
\hline & "3" & $\begin{array}{l}\text { Capture of a } 4 \text { yo independent } \\
\text { subadult female }\end{array}$ \\
\hline & "4" & $\begin{array}{l}\text { Capture of a } 5 y o \text { independent } \\
\text { subadult female }\end{array}$ \\
\hline & "5" & $\begin{array}{l}\text { Capture of a mother with one } \\
\text { dependent cub of the year }\end{array}$ \\
\hline & "6" & $\begin{array}{l}\text { Capture of a mother with two } \\
\text { dependent cub of the year }\end{array}$ \\
\hline & "7" & $\begin{array}{l}\text { Capture of a mother with one } \\
\text { dependent yearling }\end{array}$ \\
\hline & "8" & $\begin{array}{l}\text { Capture of a mother with two } \\
\text { dependent yearlings }\end{array}$ \\
\hline & "9" & $\begin{array}{l}\text { Capture of a mother with one } \\
\text { dependent two-year-old } \\
\text { offspring }\end{array}$ \\
\hline & "10" & $\begin{array}{l}\text { Capture of a mother with two } \\
\text { dependent two-year-old } \\
\text { offspring }\end{array}$ \\
\hline & "11" & $\begin{array}{l}\text { Capture of an adult female } \\
\text { without dependent offspring }\end{array}$ \\
\hline & "O" & Non observation \\
\hline
\end{tabular}

between states from one year to the next. The transition rates correspond here to the demographic parameters corrected for imperfect detection and state uncertainty. Below, we describe the general procedure to specify the model by defining the states and state-tostate transition process, then the events and observation process. However, for simplicity, the events and states are chosen to match the polar bear life cycle (i.e., females are captured in spring, alone or together with a litter of one or two dependent offspring; offspring gain independence in the year following their second birthday, and offspring cannot survive the loss of their mother before gaining independence). The resulting model assumptions and its applicability to other species are discussed below.

\subsubsection{Specification of states and state process}

One specificity of our model lies in the use of CR histories based on family groups instead of individuals, which permits to include the multiple-year dependency among the caring parent and dependent offspring's demographic rates and life history traits. Below, we describe the specification of 24 unique states and 6 matrices needed to construct the model.

States correspond to the "real" demographic states of the individuals composing the family. We consider 12 states $S, S=\{J 2, J 3$,
SA4, SA5, A01, A02, A11, A12, AS1, AS2, A, D\}, to represent the polar bear life cycle (defined in Table 1 ). In addition, we specify 13 intermediary states $S^{\prime}, S^{\prime}=\{J 3$, SA4, SA5, A11, A12, AS1, AS2, A0-, A1-, I/AS1, I/AS2, A, D $\}$, and 16 intermediary states $S^{\prime \prime}, S^{\prime \prime}=\{J 3, S A 4$, SA5, A11, A12, AS1, AS2, B/A0-, NB/A0-, B/A1-, NB/A1-, B/AS, NB/ $A S, B / A, N B / A, D$, leading to a total of 24 unique states (defined in Table 1). The specification of intermediary states is what permits to distinguish between failed and successful breeders in the transition matrix to consider the influence of past reproductive history on parameters (see below).

The model is conditioned upon first capture. The initial state vector, $\mathbf{s}_{0}$, gathers the proportions of family units in each state $S$ at first capture, $s_{0}=\left(\pi_{1}, \ldots, \pi_{11}, 0\right)^{\prime}$ ( with $\pi_{12}=0$ for state $D$, because an individual must be alive at first capture).

The transition matrix, $\Psi$ describing all possible state-to-state transitions from spring one year $(t)$ to spring the next year $(t+1)$, is obtained as the matrix product of four matrices $\Psi=\Phi \cdot \Psi_{1} \cdot \Psi_{2} \cdot \Psi_{3}$. This decomposition is another particularity of our model which permits to estimate the relevant set of demographic parameters: independent juvenile, subadult and adult survival (matrix $\Phi$ ), dependent offspring survival (matrix $\Psi_{1}$ ), breeding probabilities (matrix $\Psi_{2}$ ), and litter size probabilities (matrix $\Psi_{3}$ ), and potential trade-offs among them. This formulation of the transition matrix implies that litter size is conditioned upon breeding decision, itself conditioned upon offspring survival, itself conditioned upon survival of the caring parent to deal with the statistical dependency existing among individuals within family units.

The $\Phi$ matrix (Equation 1) describes transitions from each state $S$ at time $t$ (rows) to each state $S$ after the occurrence of the survival process for independent individuals (columns):

J2 J3 SA4 SA5 A01 A02 A11 A12 AS1 AS2 A D

$\begin{array}{ccccccccccccc}\mathrm{J} 2 & \varphi_{1} & 0 & 0 & 0 & 0 & 0 & 0 & 0 & 0 & 0 & 0 & 1-\varphi_{1} \\ \mathrm{~J} 3 & 0 & \varphi_{2} & 0 & 0 & 0 & 0 & 0 & 0 & 0 & 0 & 0 & 1-\varphi_{2} \\ \mathrm{SA} 4 & 0 & 0 & \varphi_{3} & 0 & 0 & 0 & 0 & 0 & 0 & 0 & 0 & 1-\varphi_{3} \\ \mathrm{SA} 5 & 0 & 0 & 0 & \varphi_{4} & 0 & 0 & 0 & 0 & 0 & 0 & 0 & 1-\varphi_{4} \\ \mathrm{~A} 01 & 0 & 0 & 0 & 0 & \varphi_{5} & 0 & 0 & 0 & 0 & 0 & 0 & 1-\varphi_{5} \\ \mathrm{~A} 02 & 0 & 0 & 0 & 0 & 0 & \varphi_{6} & 0 & 0 & 0 & 0 & 0 & 1-\varphi_{6} \\ \mathrm{~A} 11 & 0 & 0 & 0 & 0 & 0 & 0 & \varphi_{7} & 0 & 0 & 0 & 0 & 1-\varphi_{7} \\ \mathrm{~A} 12 & 0 & 0 & 0 & 0 & 0 & 0 & 0 & \varphi_{8} & 0 & 0 & 0 & 1-\varphi_{8} \\ \mathrm{AS} 1 & 0 & 0 & 0 & 0 & 0 & 0 & 0 & 0 & \varphi_{9} & 0 & 0 & 1-\varphi_{9} \\ \mathrm{AS} 2 & 0 & 0 & 0 & 0 & 0 & 0 & 0 & 0 & 0 & \varphi_{10} & 0 & 1-\varphi_{10} \\ \mathrm{~A} & 0 & 0 & 0 & 0 & 0 & 0 & 0 & 0 & 0 & 0 & \varphi_{11} & 1-\varphi_{11} \\ \mathrm{D} & 0 & 0 & 0 & 0 & 0 & 0 & 0 & 0 & 0 & 0 & 0 & 1\end{array}$

In the $\Phi$ matrix, $\varphi_{1}, \ldots \varphi_{11}$ correspond to survival of immature independent (juveniles and subadults) and adult female bears.

The $\Psi_{1}$ matrix (Equation 2) describes transitions from states $S$ after the occurrence of the survival process for independent individuals (rows) to states $\mathrm{S}^{\prime}$ after the occurrence of the offspring survival process (columns): 


\begin{tabular}{|c|c|c|c|c|c|c|c|c|c|c|c|c|}
\hline \multicolumn{4}{|c|}{ J3 SA4 SA5 } & \multirow{2}{*}{$\begin{array}{c}\text { A11 } \\
0\end{array}$} & \multirow{2}{*}{$\begin{array}{c}\mathrm{A} 12 \\
0\end{array}$} & \multirow{2}{*}{$\begin{array}{c}\text { AS1 } \\
0\end{array}$} & \multirow{2}{*}{$\begin{array}{c}\text { AS2 } \\
0\end{array}$} & \multirow{2}{*}{$\begin{array}{c}\mathrm{A} 0- \\
0\end{array}$} & \multirow{2}{*}{$\begin{array}{c}\mathrm{A} 1- \\
0\end{array}$} & \multicolumn{3}{|c|}{ I/AS1 I/AS2 A D } \\
\hline J2 & 1 & 0 & 0 & & & & & & & 0 & 0 & 00 \\
\hline J3 & 0 & 1 & 0 & 0 & 0 & 0 & 0 & 0 & 0 & 0 & 0 & 00 \\
\hline SA4 & & 0 & $1-\kappa$ & 0 & 0 & 0 & 0 & 0 & 0 & 0 & 0 & $\kappa 0$ \\
\hline SA5 & & 0 & 0 & 0 & 0 & 0 & 0 & 0 & 0 & 0 & 0 & 10 \\
\hline A01 & & 0 & 0 & $s_{1}$ & 0 & 0 & 0 & $1-s_{1}$ & 0 & 0 & 0 & 00 \\
\hline A02 & & 0 & 0 & $2 \cdot s_{2} \cdot\left(1-s_{2}\right)$ & $s_{2}^{2}$ & 0 & 0 & $1-s_{2}^{2}-2 \cdot s_{2} \cdot\left(1-s_{2}\right)$ & 0 & 0 & 0 & 00 \\
\hline A11 & & 0 & 0 & 0 & 0 & $s_{3}{ }^{(2)}$ & 0 & 0 & $1-s_{3}$ & 0 & 0 & 00 \\
\hline A12 & & 0 & 0 & 0 & 0 & $2 \cdot s_{4} \cdot\left(1-s_{4}\right)$ & $s_{4}^{2}$ & 0 & $1-s_{4}^{2}-2 \cdot s_{4} \cdot\left(1-s_{4}\right)$ & 0 & 0 & 00 \\
\hline AS1 & & 0 & 0 & 0 & 0 & 0 & 0 & 0 & 0 & 1 & 0 & 00 \\
\hline AS2 & 0 & 0 & 0 & 0 & 0 & 0 & 0 & 0 & 0 & 0 & 1 & 00 \\
\hline A & 0 & 0 & 0 & 0 & 0 & 0 & 0 & 0 & 0 & 0 & 0 & 10 \\
\hline D & 0 & 0 & 0 & 0 & 0 & 0 & 0 & 0 & 0 & 0 & 0 & 01 \\
\hline
\end{tabular}

In the $\Psi_{1}$ matrix, $\kappa$ is the probability of first reproduction at age $5, s$ is dependent offspring survival conditioned upon mother survival $\left(s_{1}\right.$ for singleton cub, $s_{2}$ for singleton yearling, $s_{3}$ for twin litter's
The $\Psi_{2}$ matrix (Equation 3) describes transitions from states $S^{\prime}$ after occurrence of the survival processes (rows) to states $S^{\prime \prime}$ depending on breeding decision (columns):

\begin{tabular}{|c|c|c|c|c|c|c|c|c|c|c|c|c|c|c|c|}
\hline J3 & 1 & 0 & 0 & 0 & 0 & 0 & 0 & 0 & 0 & 0 & 0 & 0 & 0 & 0 & 0 \\
\hline SA4 & 0 & 1 & 0 & 0 & 0 & 0 & 0 & 0 & 0 & 0 & 0 & 0 & 0 & 0 & 0 \\
\hline SA5 & 0 & 0 & 1 & 0 & 0 & 0 & 0 & 0 & 0 & 0 & 0 & 0 & 0 & 0 & 0 \\
\hline A11 & 0 & 0 & 0 & 1 & 0 & 0 & 0 & 0 & 0 & 0 & 0 & 0 & 0 & 0 & 0 \\
\hline A12 & 0 & 0 & 0 & 0 & 1 & 0 & 0 & 0 & 0 & 0 & 0 & 0 & 0 & 0 & 0 \\
\hline A21 & 0 & 0 & 0 & 0 & 0 & 1 & 0 & 0 & 0 & 0 & 0 & 0 & 0 & 0 & 0 \\
\hline A22 & 0 & 0 & 0 & 0 & 0 & 0 & 1 & 0 & 0 & 0 & 0 & 0 & 0 & 0 & 0 \\
\hline AO- & 0 & 0 & 0 & 0 & 0 & 0 & 0 & $\beta_{1}$ & $1-\beta_{1}$ & 0 & 0 & 0 & 0 & 0 & 0 \\
\hline A1- & 0 & 0 & 0 & 0 & 0 & 0 & 0 & 0 & 0 & $\beta_{2}$ & $1-\beta_{2}$ & 0 & 0 & 0 & 0 \\
\hline I/AS1 & 0 & 0 & 0 & 0 & 0 & 0 & 0 & 0 & 0 & 0 & 0 & $\beta_{3}$ & $1-\beta_{3}$ & 0 & 0 \\
\hline I/AS2 & 0 & 0 & 0 & 0 & 0 & 0 & 0 & 0 & 0 & 0 & 0 & $\beta_{3}$ & $1-\beta_{3}$ & 0 & 0 \\
\hline A & 0 & 0 & 0 & 0 & 0 & 0 & 0 & 0 & 0 & 0 & 0 & 0 & 0 & $\beta_{4}$ & $1-\beta_{4}$ \\
\hline D & 0 & 0 & 0 & 0 & 0 & 0 & 0 & 0 & 0 & 0 & 0 & 0 & 0 & 0 & 0 \\
\hline
\end{tabular}

individual cub, and $s_{4}$ for twin litter's individual yearling). Litter survival rates can be obtained from individual offspring survival rates (for singleton litters $I_{01}=s_{1}$ and $I_{11}=s_{3}$ for cub and yearling, respectively, and for twin litters $I_{02}=1-\left(1-s_{2}^{2}-2 \cdot s_{2} \cdot\left(1-s_{2}\right)\right)$ and $I_{12}=1-\left(1-s_{4}^{2}-2 \cdot s_{4} \cdot\left(1-s_{4}\right)\right)$ for cubs and yearlings, respectively).
Parameter $\beta$ is breeding probability conditioned upon mother and offspring's survival status ( $\beta_{1}$ following loss of a cub litter, $\beta_{2}$ loss of a yearling litter, $\beta_{3}$ for successful breeder, $\beta_{4}$ for female without dependent offspring at the beginning of the year).

The $\Psi_{3}$ matrix (Equation 4) describes transitions from states $S^{\prime \prime}$ after occurrence of the survival processes and breeding decision 
(rows) to states $\mathrm{S}$ at $t+1$ after determination of litter size for breeders (columns):

\section{J2 J3 SA4 SA5 A01 A02 A11 A12 AS1 AS2 A D}

$\begin{array}{ccccccccccccc}\text { J3 } & 0 & 1 & 0 & 0 & 0 & 0 & 0 & 0 & 0 & 0 & 0 & 0 \\ \text { SA4 } & 0 & 0 & 1 & 0 & 0 & 0 & 0 & 0 & 0 & 0 & 0 & 0 \\ \text { SA5 } & 0 & 0 & 0 & 1 & 0 & 0 & 0 & 0 & 0 & 0 & 0 & 0 \\ \text { A11 } & 0 & 0 & 0 & 0 & 0 & 0 & 1 & 0 & 0 & 0 & 0 & 0 \\ \text { A12 } & 0 & 0 & 0 & 0 & 0 & 0 & 0 & 1 & 0 & 0 & 0 & 0 \\ \text { AS1 } & 0 & 0 & 0 & 0 & 0 & 0 & 0 & 0 & 1 & 0 & 0 & 0 \\ \text { AS2 } & 0 & 0 & 0 & 0 & 0 & 0 & 0 & 0 & 0 & 1 & 0 & 0 \\ \text { B/A0- } & 0 & 0 & 0 & 0 & \gamma_{1} & 1-\gamma_{1} & 0 & 0 & 0 & 0 & 0 & 0 \\ \text { NB/A0- } & 0 & 0 & 0 & 0 & 0 & 0 & 0 & 0 & 0 & 0 & 1 & 0 \\ \text { B/A1- } & 0 & 0 & 0 & 0 & \gamma_{2} & 1-\gamma_{2} & 0 & 0 & 0 & 0 & 0 & 0 \\ \text { NB/A1- } & 0 & 0 & 0 & 0 & 0 & 0 & 0 & 0 & 0 & 0 & 1 & 0 \\ \text { B/AS1 } & 0 & 0 & 0 & 0 & \gamma_{3} & 1-\gamma_{3} & 0 & 0 & 0 & 0 & 0 & 0 \\ \text { B/AS2 } & 0 & 0 & 0 & 0 & \gamma_{3} & 1-\gamma_{3} & 0 & 0 & 0 & 0 & 0 & 0 \\ \text { B/A } & 0 & 0 & 0 & 0 & \gamma_{4} & 1-\gamma_{4} & 0 & 0 & 0 & 0 & 0 & 0 \\ \text { NB/A } & 0 & 0 & 0 & 0 & 0 & 0 & 0 & 0 & 0 & 0 & 1 & 0 \\ \text { D } & 0 & 0 & 0 & 0 & 0 & 0 & 0 & 0 & 0 & 0 & 0 & 1\end{array}$

Parameter $\gamma$ is the probability of producing a singleton litter conditioned upon mother's and offspring's survival status and upon breeding decision ( $\gamma_{1}$ following the loss a cub litter, $\gamma_{2}$ loss of a yearling litter, $\gamma_{3}$ for successful breeder, $\gamma_{4}$ for female without dependent offspring at the beginning of the year).

By modifying the constraints on parameters (i.e., setting them equal or different among states), the model can be used to investigate (a) the cost of reproduction on parent's survival (by comparing the $\varphi s$ in matrix $\Phi$ ), (b) the influence of litter size on individual offspring survival (by comparing $s_{1}$ to $s_{2}$, and $s_{3}$ to $s_{4}$ in matrix $\Psi_{1}$ ) and on litter survival (by comparing $I_{01}$ to $I_{02}$ and $I_{11}$ to $I_{12}$ ), (d) the influence of past reproductive history on breeding probability (by comparing the $\beta$ s in matrix $\Psi_{2}$ ), and on litter size probability (by comparing the $\gamma \mathrm{s}$ in matrix $\Psi_{3}$ ).

\subsection{3 | Specification of events and observation process}

The events correspond to the observation or nonobservation of family units in the field at each sampling occasion. Each event is coded depending on the number and age of the individuals composing the family. Here, we consider 12 possible events, $\Omega=\{1,2,3,4,5,6,7,8,9,10,11,12\}$ to describe field observations for polar bears family groups (defined in Table 1).

In a multievent model, one specific event may relate to several possible states. Due to variable timing at offspring independence, a female successful breeder (state "AS1" or "AS2") can be captured together with 1 or 2 two-year-old dependent offspring (event "9" or "10") or without (event "11") its two-year-old offspring or not captured (event "12") depending on (a) whether the offspring has already departed from its mother at the time of capture and (b) on capture probability. To include uncertainty on state assignment due to variable timing at offspring independence, we decompose the observation process into two event matrices, $E_{1}$ and $E_{2}$, modeling, respectively, departure probability $(\alpha)$ and capture probability $(p)$.

The $E_{1}$ matrix (Equation 5 ) relates the states $S$ to the possible observations at the time of capture, $\mathrm{O}=\{1,2,3,4,5,6,7,8,9,10,11,12\}$ (same code as the events, see Table 1), through the departure probability, denoted $\alpha$.

$\begin{array}{rrrrrr}1223456678 & 9 & 10 & 11 \\ \text { J2 } 1000000000 & 0 & 0 & 0 & 0 \\ \text { J3 } 010000000 & 0 & 0 & 0 & 0 \\ \text { SA4 } 001000000 & 0 & 0 & 0 & 0 \\ \text { SA5 } 0000100000 & 0 & 0 & 0 & 0 \\ \text { A01 } 0000010000 & 0 & 0 & 0 & 0 \\ \text { A02 } 00000001000 & 0 & 0 & 0 & 0 \\ \text { A11 } 0000000010 & 0 & 0 & 0 & 0 \\ \text { A12 } 0000000001 & 0 & 0 & 0 & 0 \\ \text { AS1 } 0000000000 & 1-\alpha_{i, d} & 0 & \alpha_{i, d} & 0 \\ \text { AS2 } 000000000002 \cdot \alpha_{i, d} \cdot\left(1-\alpha_{i, d}\right) 1-2 \cdot \alpha_{i . d} \cdot\left(1-\alpha_{i, d}\right)-\alpha_{i, d}^{2} & \alpha_{i, d}^{2} & 0 \\ \text { A } 0000000000 & 0 & 0 & 1 & 0 \\ \text { D } 0000000000 & 0 & 0 & 0 & 1\end{array}$

Here, $\alpha_{i, d}$ is the departure probability of a two-year-old individual offspring belonging to family unit $i$ on its date of capture $d$. The relationship between date of capture and departure probability is speciesspecific and either assessed from prior knowledge on the species' biology or field data (see Appendix S2). Here, we assume that siblings' timing at independence can, but does not have to, occur independently (if both offspring can only depart the family on the same date, the transition from state "AS2" to event "9" should be set to 0 ).

The second event matrix, $E_{2}$, (Equation 6) relates all possible observations at the time of capture $O$ to the events, $\Omega$, actually observed in the field through the state-dependent capture probability, denoted $p_{\mathrm{s}}$.

$$
\begin{array}{ccccccccccccc} 
& 1^{\prime} & 2^{\prime} & 3^{\prime} & 4^{\prime} & 5^{\prime} & 6^{\prime} & 7^{\prime} & 8^{\prime} & 9^{\prime} & 10^{\prime} & 11^{\prime} & 12^{\prime} \\
1^{\prime} & p_{1} & 0 & 0 & 0 & 0 & 0 & 0 & 0 & 0 & 0 & 0 & 1-p_{1} \\
2^{\prime} & 0 & p_{2} & 0 & 0 & 0 & 0 & 0 & 0 & 0 & 0 & 0 & 1-p_{2} \\
3^{\prime} & 0 & 0 & p_{3} & 0 & 0 & 0 & 0 & 0 & 0 & 0 & 0 & 1-p_{3} \\
4^{\prime} & 0 & 0 & 0 & p_{4} & 0 & 0 & 0 & 0 & 0 & 0 & 0 & 1-p_{4} \\
5^{\prime} & 0 & 0 & 0 & 0 & p_{5} & 0 & 0 & 0 & 0 & 0 & 0 & 1-p_{5} \\
6^{\prime} & 0 & 0 & 0 & 0 & 0 & p_{6} & 0 & 0 & 0 & 0 & 0 & 1-p_{6} \\
7^{\prime} & 0 & 0 & 0 & 0 & 0 & 0 & p_{7} & 0 & 0 & 0 & 0 & 1-p_{7} \\
8^{\prime} & 0 & 0 & 0 & 0 & 0 & 0 & 0 & p_{8} & 0 & 0 & 0 & 1-p_{8} \\
9^{\prime} & 0 & 0 & 0 & 0 & 0 & 0 & 0 & 0 & p_{9} & 0 & 0 & 1-p_{9} \\
10^{\prime} & 0 & 0 & 0 & 0 & 0 & 0 & 0 & 0 & 0 & p_{10} & 0 & 1-p_{10} \\
11^{\prime} & 0 & 0 & 0 & 0 & 0 & 0 & 0 & 0 & 0 & 0 & p_{11} & 1-p_{11} \\
12^{\prime} & 0 & 0 & 0 & 0 & 0 & 0 & 0 & 0 & 0 & 0 & 0 & 1
\end{array}
$$


The composite event matrix, $E$, which relates the events to the states, is obtained as the matrix product of these two matrices $E=E_{1} \cdot E_{2}$. Because the model is conditioned upon first capture, the initial event vector, $e_{0}$, takes the value of 1 for all events (except of 0 for the event " 12 " corresponding to a nonobservation).

\subsubsection{Applicability to other species}

The model described above matches the Svalbard polar bear life cycle. The model therefore assumes that care is provided by the mother only, to one or two offspring (we modelled triplets as twins because there were just 8 litters of triplets in the data), for a duration of two years maximum. Offspring under age 2 cannot survive if the mother dies. A mother caring for offspring cannot mate and produce a second litter. Independent males (that have already departed from the family unit) are not included in the model.

To apply the model to other species, one should modify the number of events and states to match the species life cycle (depending on age at sexual maturity, number of care providers, maximum litter size, duration of parental care) but the number of matrices should remain the same. For example, modeling a hypothetical species similar to polar bears but in which both males and females care for offspring would increase the number of unique states from 24 to 42 (8 states for immature females and males, 21 states for dependent offspring cared for by both parents, just the mother in case of father loss, or just the father in case of mother loss). Such a model could be used to assess the influence of father versus mother loss on litter size, offspring survival, and father and/or mother breeding probabilities. After defining the states and events, one should modify the shape of the relationship between departure probability and date of capture to match the species life cycle. In species like primates or wolves, departure from the family unit can occur throughout the year, at a more or less constant rate depending on the season, while it occurs only between February and May in polar bears due to environmental constraints. In addition, the influence of individual traits such as age or body weight, or environmental variables such as temperature, can be included in the model under the form of individual or temporal covariates (Pollock, 2002). Other specificities related to data collection can be included in a similar way, such as trap effects (Pradel \& SanzAguilar, 2012) or latent individual heterogeneity by using mixture of distributions or random effects (Gimenez et al., 2018). Guidance to fit the model in a Bayesian framework in program Jags for real and simulated data are provided in Appendices 1 and 2.

\section{2 | Simulation study}

The simulation study was aimed at evaluating the performance of our model to estimate demographic parameters under various assumptions about the timing at offspring independence (constant vs. seasonal departure rate) and various degrees of capture probability (low $p=.25$, high $p=.7$ ), for a medium-size dataset ( $T=15$ sampling occasions, with $R=80$ newly marked at each occasion in equal proportion among the 11 alive states).

We simulated data for a virtual long-lived mammal species mimicking the polar bear using the model described in section 1 above. We used $\varphi=0.9$ for independent female bear survival (aged $2+$ y.o.), $s_{1}=I_{01}=0.6$ for singleton cub survival, $s_{2}=0.55$ for twin litter' $\mathrm{s}$ cub survival (corresponding to twin litter survival $I_{02}=0.7975$ ), $s_{3}=0.8$ for singleton yearling survival, and $s_{4}=0.75$ for twin litter's yearling survival (corresponding to litter survival $I_{12}=0.94$ ). Offspring survival rates were conditioned upon mother survival. If a mother dies, its dependent offspring had no chances of surviving. For breeding probabilities, we used $\beta_{1}=0.5, \beta_{2}=0.7, \beta_{3}=0.9$, and $\beta_{4}=0.8$. For litter size probabilities, we used $\gamma_{1}=0.4, \gamma_{2}=0.5, \gamma_{3}=0.6$, and $\gamma_{4}=0.7$. We set $\kappa=0$ and assumed that females had their first litter at age 6 or older.

We assumed that captures occurred each year between midMarch to end of May (day of the year $d=80$ to $d=130$ ). For each capture event, date of capture was randomly sampled from the distribution of the polar bear data dates of capture (see Appendix S1). In the constant scenario, we assumed that two-year-old bears reached independence at a constant departure rate $(\alpha)$ during the field season, independently of the date of capture. We chose an intermediate value of $\alpha=0.5$ (if independence occurred always after the field season, $\alpha=0$, vs. always before the field season, $\alpha=1$ ). In the seasonal scenario, we assumed that departure rate varied with date of capture (d) following a logistic relationship (regression coefficients were estimated from the polar bear data, see Appendix S2). Most of the two-year-old offspring were captured with their mother at the beginning of the field season, while departure probability increased logistically up to $80 \%$ at the end of the field season.

We simulated $100 \mathrm{CR}$ datasets for each of the four scenarios (S1: low detection with constant departure, S2: low detection with seasonal departure, S3: high detection with constant departure, S4: high detection with seasonal departure). We simulated the data using program $\mathrm{R}$. We fitted the model using program jags called from $\mathrm{R}$ (Plummer et al., 2016). For each parameter and each dataset, we calculated absolute bias as $\widehat{B}=\widehat{\theta}-\theta$, and root mean squared error as $\widehat{R M S E}=\sqrt{(\hat{\theta}-\theta)^{2}}$, with $\theta$ the parameter used to simulate the data and $\hat{\theta}$ the mean value of the estimated parameter. Appendix S1 containing guidance, $\mathrm{R}$ code, and files to simulate data and fit the model is available on GitHub at https://github.com/SCubaynes/Appen dix1_extendedparentalcare.

\section{3 | Case study: polar bears in Svalbard}

In polar bears, care of offspring is provided by the mother only (Amstrup \& DeMaster, 2003). Males were therefore discarded from our analysis. Adult female polar bears mate in spring (February to May, Amstrup \& DeMaster, 2003), and in Svalbard usually have their first litter at the age of six years, but some females can have their first litter at five years (Derocher \& Stirling, 1994; Derocher, 2013). They have delayed implantation where the egg attaches to the uterus in 


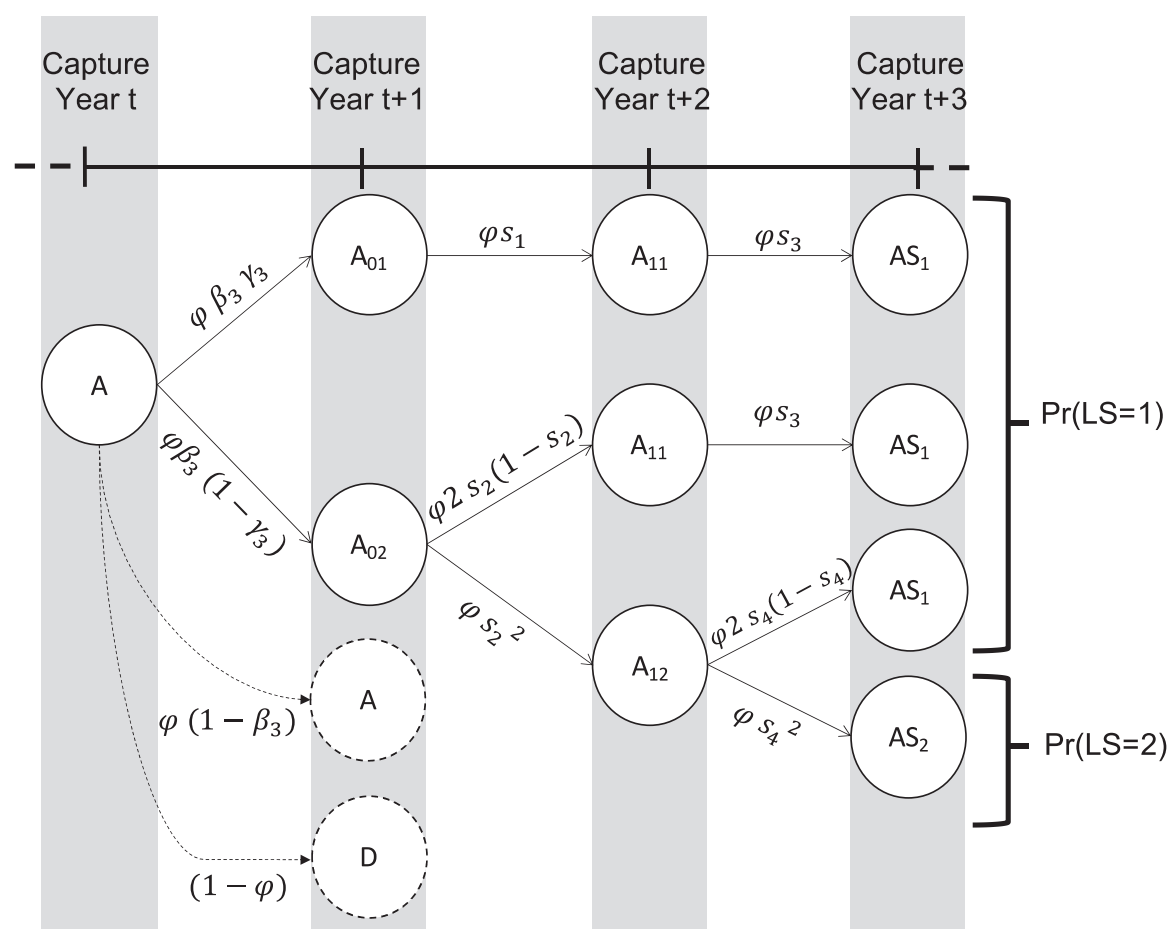

FIGURE 1 Life history events with associated probabilities of raising one $(X=1)$ or two $(X=2)$ offspring to independence over a 3-year period for a female polar bear alive and without dependent offspring at the beginning of the period (state A). State A01 represents a female with one dependent cub of the year, A02 with two dependent cubs of the year, A11 with one dependent yearling, A12 with two dependent yearlings, AS1 a successful female breeder with one two-year-old offspring reaching independence, and AS2 a successful female breeder with two two-year-old offspring reaching independence. Parameter $\varphi$ is adult survival, $\beta_{3}$ is breeding probability of a female without dependent offspring, $\gamma_{3}$ is the probability of a singleton litter, $s_{1}$ is cub and $s_{2}$ is yearling survival in a singleton litter, and $s_{3}$ is cub and $s_{4}$ is yearling survival in a twin litter

autumn (Ramsay \& Stirling, 1988). A litter with small cubs (ca $600 \mathrm{~g}$ ) is born around November to January, in a snow den that the mothers dig out in autumn, and where the family stay 4-5 months. The family usually emerges from the den in March-April and stay close to the den while the cubs get accustomed to the new environment outside their home, for a few days up to 2-3 weeks (Hansson \& Thomassen, 1983). Litter size in early spring vary from one to three, with two cubs being most common, three cubs in most areas being rare, and commonly around one out of three litters having one cub only (Amstrup \& DeMaster, 2003). In Svalbard, polar bears become independent from their mother shortly after their second birthday (average age at independence is 2.3). Two-year-old bears typically depart from the mother in spring (between mid-March and end of May), when the mother can mate again. There is only one anecdotal record of a yearling alive without his mother. Because the field season can last for several weeks, some two-year-old bears were captured together with their mother and others were already independent at the time of capture. The minimum reproductive interval for successful Barents Sea polar bears is 3 years. On the contrary, loss of a cub litter shortly after den emergence may mean the mother can produce new cubs in winter the same year (Ramsay \& Stirling, 1988).

Bears captured in Svalbard are shown to be a mixture of resident and pelagic bears (Mauritzen et al., 2002). To focus on the resident population, independent bears captured only once were not included in our analysis. We therefore analyzed $N=158$ encounter histories of resident polar bear family units captured each spring after den emergence between doy 80 and 130 (mid-March to midMay), from 1992 to 2019, in Svalbard. It corresponds to 81 capture events of juvenile and subadults, 231 cubs, 96 yearling, 23 dependent two-year-old, and 444 captures of adult females. Polar bears were caught and individually marked as part of a long-term monitoring program on the ecology of polar bears in the Barents Sea region (Derocher, 2005). All bears one year or older were immobilized by remote injection of a dart (Palmer Cap-Chur Equipment) with the drug Zoletil ${ }^{\circledR}$ (Virbac) (Stirling et al., 1989). The dart was fired from a small helicopter (Eurocopter 350 B2 or B3), usually from a distance of about 4 to $10 \mathrm{~m}$. Cubs of the year were immobilized by injection with a syringe. Cubs and yearlings were highly dependent on their mother; therefore, they remained in her vicinity and were captured together with their mother. A female captured alone was considered to have no dependent offspring alive. Death of the cubs could have occurred in the den or shortly after den emergence but before capture. Hereafter, estimated cub survival thus refers to survival after capture. Infant mortality occurring before capture will be assigned to a reduced litter size. Because only $3 \%$ of females were observed with 3 offspring, we analyzed jointly litters of twins with triplets.

We built the model described above with 12 states and 12 events to describe the life cycle (Table 1). Preliminary analyses suggested 


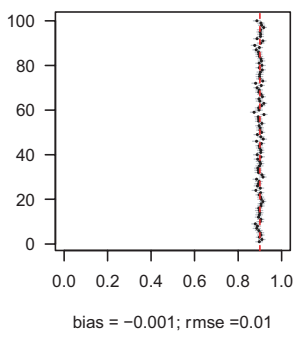

$\mathrm{S}_{4}$

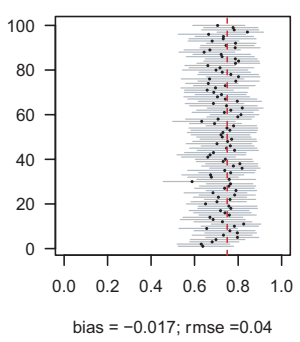

$\gamma_{1}$

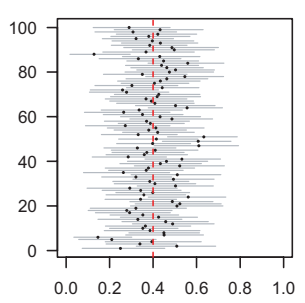

bias $=0.001 ;$ rmse $=0.07$ $\kappa$

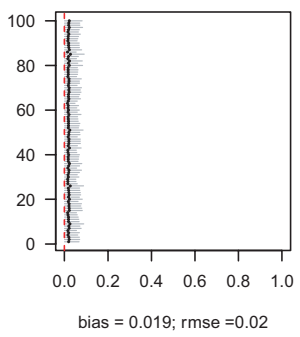

$\beta_{1}$

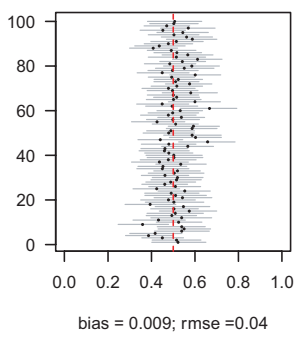

$\gamma_{2}$

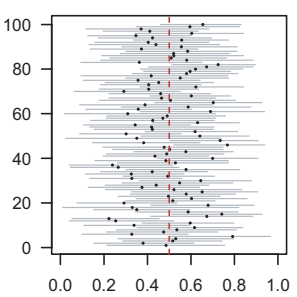

bias $=-0.005 ;$ rmse $=0.11$
$\mathrm{S}_{1}$

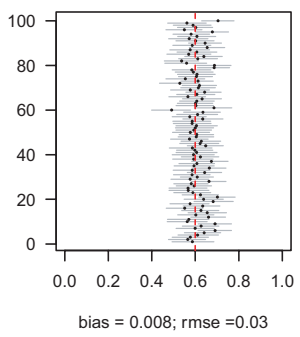

$\beta_{2}$
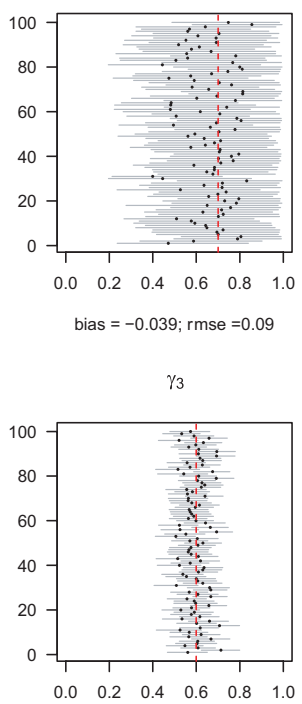

bias $=-0.003 ;$ rmse $=0.04$
$\mathrm{S}_{2}$

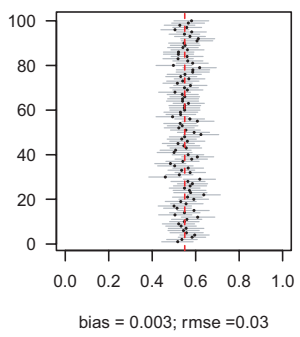

$\beta_{3}$
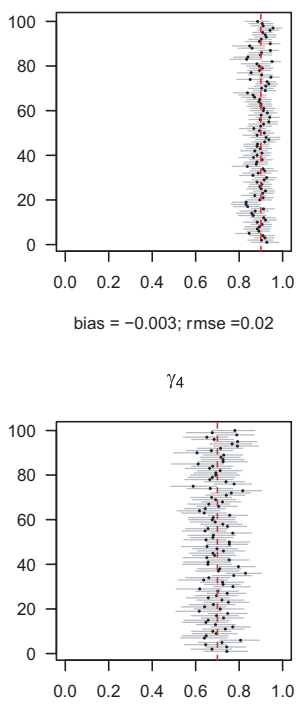

bias $=0.002 ;$ rmse $=0.04$
$\mathrm{S}_{3}$

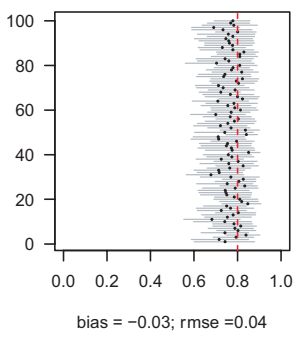

$\beta_{4}$
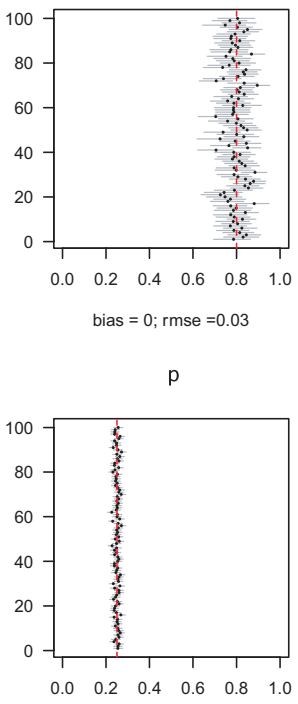

bias $=0 ;$ rmse $=0.01$

FIGURE 2 Performance of the model on simulated data with low detection with seasonal departure (scenario S2). For each of the 100 simulated datasets, we displayed the mean (circle) and the $95 \%$ confidence interval (horizontal solid line) of the parameter. The actual value of the parameter is given by the vertical dashed red line. The estimated absolute bias and root-mean-square error are provided in the legend of the $X$-axis for each parameter. Regarding notations, $\phi$ stands for juvenile, subadult and adult survival, $\kappa$ is the probability of first reproduction at age $5, s$ is dependent offspring survival conditioned upon mother survival $\left(s_{1}\right.$ and $s_{2}$ for singleton cub resp. yearling; $s_{3}$ and $s_{4}$ for twin litter's cub resp. yearling), $\beta$ is breeding probability conditioned upon mother and offspring survival status ( $\beta_{1}$ following loss of a cub litter, $\beta_{2}$ loss of a yearling litter, $\beta_{3}$ for successful breeder, $\beta_{4}$ for female without dependent offspring), $\gamma$ is the probability of producing a singleton litter conditioned upon mother's and offspring's survival status and upon breeding decision $\left(\gamma_{1}\right.$ following loss of a cub litter, $\gamma_{2}$ loss of a yearling litter, $\gamma_{3}$ for successful breeder, $\gamma_{4}$ for female without dependent offspring), and $p$ is detection probability

that mother survival did not vary according to state, we therefore constrained parameter $\varphi$ to be equal among all states in matrix $\Phi$. To avoid identifiability issues due to a relatively small sample size, we assumed breeding probability and litter size probability did not vary between successful breeders (states AS1 and AS2) and female without dependent offspring (state A) by setting $\beta_{3}=\beta_{4}$ and $\gamma_{3}=\gamma_{4}$. We also assumed that litter size probability did not vary among failed breeders (loss of a cub vs. a yearling litter), by setting $\gamma_{1}=\gamma_{2}$. We could not assess formally the fit of our model because no test is yet available for multievent models. However, the multistate version of our model (without uncertainty on timing at independence) fitted the data adequately. Adding a level of complexity should make the model even more adequate.

Using the conditional probabilities estimated in the model, we calculated the net probability for a female to raise none,
$\operatorname{Pr}(X=0)$, one, $\operatorname{Pr}(X=1)$, or two offspring, $\operatorname{Pr}(X=2)$ to independence over a 3-year period (Figure 1, further details are provided in Appendix S2).

We considered adult females without dependent offspring at the beginning of the time period, so that we have:

$\operatorname{Pr}(X=1)=\varphi^{3} \cdot \beta_{3} \cdot\left[\gamma_{3} \cdot s_{1} \cdot s_{3}+\left(1-\gamma_{3}\right) \cdot\left(2 s_{2}\left(1-s_{2}\right) \cdot s_{3}+s_{2}^{2} \cdot 2 s_{4}\left(1-s_{4}\right)\right)\right]$

$$
\begin{gathered}
\operatorname{Pr}(X=2)=\varphi^{3} \cdot \beta_{3} \cdot\left(1-\gamma_{3}\right) \cdot s_{2}^{2} \cdot s_{4}^{2}, \\
\operatorname{Pr}(X=0)=1-\operatorname{Pr}(X=1)-\operatorname{Pr}(X=2) .
\end{gathered}
$$

Appendix S2 containing guidance, $R$ code, data files to fit the model to the polar bear data, and additional results is available on GitHub at https://github.com/SCubaynes/Appendix2_extendedparentalcare. 
TABLE 2 Parameter estimates

\begin{tabular}{|c|c|c|c|c|}
\hline Parameter & Notation & Mean & $\begin{array}{l}\text { Standard } \\
\text { error }\end{array}$ & $95 \% \mathrm{Cl}$ \\
\hline $\begin{array}{l}\text { Survival of female juveniles ( } 2 \text { yo, } 3 \text { yo) } \\
\text { subadults ( } 4 \text { yo, } 5 \text { yo) and adults }(5+\text { yo) }\end{array}$ & $\varphi$ & 0.93 & 0.01 & $0.92-0.95$ \\
\hline \multicolumn{5}{|l|}{ Cub survival $(<1$ yo $)$} \\
\hline Singleton (=litter survival) & $s_{1}=I_{01} I_{01}$ & 0.54 & 0.10 & $0.34-0.72$ \\
\hline Litter of 2 (averaged individual survival) & $s_{2}$ & 0.51 & 0.05 & $0.41-0.62$ \\
\hline \multicolumn{5}{|l|}{ Yearling survival (1yo) } \\
\hline Singleton (=litter survival) & $s_{3}=I_{11}$ & 0.67 & 0.11 & $0.46-0.87$ \\
\hline Litter of 2 (averaged individual survival) & $s_{4}$ & 0.80 & 0.09 & $0.59-0.93$ \\
\hline \multicolumn{5}{|l|}{ Litter survival for twin litters } \\
\hline Cubs & $I_{02}$ & 0.76 & 0.05 & $0.65-0.85$ \\
\hline Yearlings & $I_{12}$ & 0.95 & 0.04 & $0.83-0.99$ \\
\hline $\begin{array}{l}\text { Probability of first reproduction at } 5 \text { yo } \\
\text { (mate at } 4 \text { yo) }\end{array}$ & $\kappa$ & 0.12 & 0.08 & $0.02-0.30$ \\
\hline \multicolumn{5}{|l|}{ Breeding probability } \\
\hline Following loss of a cub litter & $\beta_{1}$ & 0.09 & 0.06 & $0.01-0.23$ \\
\hline Following loss of a yearling litter & $\beta_{2}$ & 0.58 & 0.21 & $0.19-0.96$ \\
\hline $\begin{array}{l}\text { Of successful female breeders or } \\
\text { previously without dependent } \\
\text { offspring }\end{array}$ & $\beta_{3}=\beta_{4}$ & 0.52 & 0.04 & $0.43-0.61$ \\
\hline \multicolumn{5}{|l|}{ Probability of singleton litter } \\
\hline Following loss of a cub or yearling litter & $\gamma_{1}=\gamma_{2}$ & 0.35 & 0.17 & $0.07-0.71$ \\
\hline $\begin{array}{l}\text { Of successful female breeders or } \\
\text { previously without dependent } \\
\text { offspring }\end{array}$ & $\gamma_{3}=\gamma_{4}$ & 0.40 & 0.05 & $0.30-0.44$ \\
\hline Capture probability & $p$ & 0.25 & 0.01 & $0.22-0.27$ \\
\hline
\end{tabular}

Note: Means are given with $95 \%$ credible intervals (CI). Dependent offspring (cub age $<1$ y.o., yearling 1 y.o.) survival and breeding probabilities are conditioned upon mother survival, litter size probability of producing a singleton is as well conditioned upon breeding decision.

\section{3 | RESULTS}

\section{1 | Model performance evaluated on simulated datasets}

Model performance was satisfying and comparable in all 4 simulated scenarios (S1 with low detection and constant departure, S2 with low detection and seasonal departure, S3 with high detection and constant departure and S4 with high detection and seasonal departure), with low average bias $\left(B_{\mathrm{S} 1}=-0.000, B_{\mathrm{S} 2}=-0.004, B_{\mathrm{S} 3}=-0.004\right.$, $\left.B_{S 4}=-0.003\right)$ and root-mean-square error $\left(\mathrm{rmse}_{\mathrm{S} 1}=0.042\right.$, rmse $_{S 2}=0.041$, rmse $_{S 3}=0.031$ and rmse $_{S 4}=0.031$ ) (see Appendix S1 for details).

For most parameters, bias was very low, $B<0.02$, except for parameters $\beta_{2}$ in scenarios S2, S3, and S4 $(-0.04<B<-0.03)$ and $s_{3}$ in scenario $S 2(B=-0.03)$, rmse $<0.05$, except for parameters $\beta_{2}, \gamma_{1}$, and $\gamma_{2}(0.05<$ rmse $<0.07)$. For these three parameters, precision was lower in the two scenarios with low detection (see Appendix S1). Estimates obtained for the scenario mimicking the polar bear study case (S2: low detection and seasonal departure) are provided in Figure 2.

\subsection{Case study: Polar bear demography}

Departure probability was about $40 \%$ at the end of March and reached $80 \%$ at mid-May (Appendix S2). About half of the two-yearold bears had departed their mother at the time of capture. Estimates of demographic parameters are provided in Table 2 (more results are provided in Appendix S2). Independent female (aged 2+) survival was high (0.93). Individual offspring survival rates, conditioned upon mother survival, did not vary significantly with litter size for cubs or yearlings. Average yearling survival was lower for singleton (0.67) than for litters of twin (0.80), although the $95 \%$ credible intervals did overlap. Concerning litter survival conditioned upon mother survival, it was higher for twin compared to singleton, for both cubs' and yearlings' litters. A small proportion of females, about $12 \%$, started to reproduce (i.e., produced a litter that survived at least until the first spring) at 5 y.o. Outcome of the previous reproduction influenced breeding probability. Breeding probability following the loss of a cub litter during the year (after capture) was low, about $10 \%$, while it was about 50\%-60\% for female' successful breeders or without dependent offspring at the beginning of the year or after the loss of a yearling litter. Detection probability was relatively low, 
about 0.25 (0.22-0.27). At first capture, 37\% were independent juvenile or subadult females, $18 \%$ were adult females alone, $28 \%$ were adult females with one or two cubs, $12 \%$ with one or two yearlings, and $5 \%$ with two-year-old bears.

Over a 3-year period, the probability to successfully raise one offspring to independence for a female polar bear, alive and without dependent offspring at the beginning of the period, was on average $0.29(0.20-0.38)$ and $0.04(0.02-0.07)$ to raise two offspring to independence. The probability of failed breeding (no offspring successfully reached independence) over this period was high, about 0.67 (0.57-0.76). Note that this calculation includes breeding probability and therefore does not reflect offspring survival until independence (see Section 2).

\section{4 | DISCUSSION}

Overall, our model performed well in estimating all demographic parameters in all the simulated scenarios. A multievent approach is a promising tool to deal with uncertainty on the timing at offspring independence both when departure probability was constant or varied within the field season. Estimates obtained for adult and offspring survival, probability of sexual maturation, breeding probability (except after the loss of a yearling litter), litter size probabilities, and detection probability were unbiased in most simulated scenarios. Precision was satisfying in most cases, but it was lower for breeding probability after the loss of a yearling litter and for litter size probabilities of failed breeders, especially in scenarios with low detection (Appendix S1). These specific parameters should therefore be interpreted with caution for the study case. In our simulations, $T=15 \mathrm{sam}$ pling occasions appeared sufficient to obtain satisfying estimates for most parameters. In the polar bear data, there were few recaptures of females on subsequent years due to relatively low detection rate. As a result, preliminary analyses suggested a potential confusion between these parameters. We dealt with this issue by including a biologically realistic constraint on prior distributions, stating that cub survival was lower than that of yearling survival (Amstrup \& Durner, 1995) which was enough to ensure parameter estimability. Inference in a Bayesian framework is useful in this regard, because it allows for the inclusion of prior information when available (McCarthy \& Masters, 2005) to improve the estimation of model parameters.

For polar bears, we showed that outcome of the previous breeding event influenced breeding probability. Reduced offspring survival one year, for example, due to poor environmental conditions (Derocher et al. 2004), might therefore increase intervals between successful reproduction through reduced breeding probability the next year (Wiig, 1998). This means that by ignoring multiple-year dependency among mother and offspring, classical models can underestimate reproductive intervals, therefore risking to overestimate the population growth rate. However, the biological relevance of our model is currently limited, because we ignored temporal and individual heterogeneity among females in the model. Survival rates for independent female bears (0.93) were close to an earlier study for the same population (0.96), based on telemetry data (Wiig, 1998). Our results may overestimate dependent offspring survival because we focused on resident bears captured more than once. Wiig (1998) results indicated that females in Svalbard went into den on average every second year (while successful breeding means denning on a three-year interval), which seems coherent with our results (about $33 \%$ chances of successful reproduction over a three-year period).

Here, we proposed a general model structure that can be applied to other species providing EPC. The originalities of our approach lie in using family structure to define statistical units in our model, and the inclusion of variable timing at offspring independence. Using families instead of individuals allows for the inclusion of dependency among individuals over multiple years and therefore the evaluation of trade-offs and correlations between offspring's and parents' life history parameters. Our model could be used, for example, to evaluate the population-level consequences of positive or negative correlation between parents' and offspring's traits (e.g., food sharing among group members Lee, 2008; or parent-offspring conflict Kölliker et al., 2013). In the case of social species (e.g., primates, elephants, orcas, wolves), several adults often play a role in caring for offspring. In addition, females often give birth to new offspring while still caring for older offspring and, above a certain age, adolescent-dependent offspring can survive despite the loss of their mother and gain independence at various ages. In such cases, the number of states to represent all possible family units' composition can rapidly increase, leading to potential computational challenges to deal with huge matrices. One solution is to use sparse matrices to store the data efficiently and optimize matrix calculations. Above this level of complexity, an alternative solution is to limit the number of states by simplifying the life cycle depending on the question of interest (e.g., focusing on mother and maternal grandmother considering only one litter, or focusing on mother caring alone for one or more litters). For polar bears specifically, future analyses will integrate in the model the effect of female age on survival and reproductive success (Atkinson \& Ramsay, 1995; Folio et al., 2019) and influence of climatic variables on body weight and demography (Derocher et al., 2004; Stirling \& Derocher, 2012) as individual and environmental covariates in a regression-like framework. Our model could then be used to provide population predictions of the demographic response of the Barents Sea polar bear population under climate change (Hunter et al., 2010; Laidre et al., 2020; Regehr et al., 2016, 2018).

\section{ACKNOWLEDGMENTS}

This study was supported by World Wildlife Fund. We thank Magnus Andersen for his participation in fieldwork and Thor Larsen for initiating the monitoring. SC is supported by a grant from the Agence Nationale de la Recherche (ANR-18-CE02-0011, MathKinD).

\section{CONFLICT OF INTEREST}

The authors declare no potential conflicts of interest.

\section{AUTHOR CONTRIBUTION}

Sarah Cubaynes: Conceptualization (lead); Data curation (lead); Formal analysis (lead); Investigation (lead); Methodology (equal); 
Writing-original draft (lead); Writing-review \& editing (lead). Jon Aars: Conceptualization (supporting); Data curation (equal); Funding acquisition (lead); Project administration (lead); Writing-original draft (supporting); Writing-review \& editing (supporting). Nigel G. Yoccoz: Conceptualization (supporting); Methodology (supporting); Writingoriginal draft (supporting); Writing-review \& editing (supporting). Roger Pradel: Conceptualization (supporting); Methodology (supporting); Writing-original draft (supporting); Writing-review \& editing (supporting). Øystein Wiig: Data curation (supporting); Project administration (supporting); Writing-original draft (supporting); Writing-review \& editing (supporting). Rolf A. Ims: Data curation (supporting); Project administration (supporting); Writing-original draft (supporting); Writing-review \& editing (supporting). Olivier Gimenez: Conceptualization (equal); Formal analysis (supporting); Investigation (supporting); Methodology (supporting); Writingoriginal draft (supporting); Writing-review \& editing (supporting).

\section{DATA AVAILABILITY STATEMENT}

All data are available in Dryad (doi:10.5061/dryad.fn2z34tsq).

\section{ORCID}

Sarah Cubaynes (iD https://orcid.org/0000-0002-3935-9825

Jon Aars (iD https://orcid.org/0000-0002-0574-6712

Nigel G. Yoccoz iD https://orcid.org/0000-0003-2192-1039

Roger Pradel iD https://orcid.org/0000-0002-2684-9251

Øystein Wiig iD https://orcid.org/0000-0003-0395-5251

Olivier Gimenez (D) https://orcid.org/0000-0001-7001-5142

\section{REFERENCES}

Amstrup, S. C., \& DeMaster, D. P. (2003). Polar bear, Ursus maritimus. In Wild mammals of North America: Biology, management, and conservation second edition (vol. 2, pp. 587-610). Baltimore, Maryland: Johns Hopkins University Press.

Amstrup, S. C., \& Durner, G. M. (1995). Survival rates of radio-collared female polar bears and their dependent young. Canadian Journal of Zoology, 73, 1312-1322. https://doi.org/10.1139/z95-155

Atkinson, S. N., \& Ramsay, M. A. (1995). The effects of prolonged fasting of the body composition and reproductive success of female polar bears (Ursus maritimus). Functional Ecology, 9(4), 559. https://doi. org $/ 10.2307 / 2390145$

Clutton-Brock, T. H. (1991). The evolution of parental care. Princeton University Press.

Cole, D. J., Morgan, B. J. T., McCrea, R. S., Pradel, R., Gimenez, O., \& Choquet, R. (2014). Does your species have memory? Analyzing capture-recapture data with memory models. Ecology and Evolution, 4(11), 2124-2133. https://doi.org/10.1002/ece3.1037

Couet, P., Gally, F., Canonne, C., \& Besnard, A. (2019). Joint estimation of survival and breeding probability in female dolphins and calves with uncertainty in state assignment. Ecology and Evolution, 9(23), 1304313055. https://doi.org/10.1002/ece3.5693

Dahle, B., \& Swenson, J. E. (2003). Factors influencing length of maternal care in brown bears (Ursus arctos) and its effect on offspring. Behavioral Ecology and Sociobiology, 54(4), 352-358. https://doi. org/10.1007/s00265-003-0638-8

Derocher, A. E. (2005). Population ecology of polar bears at Svalbard, Norway. Population Ecology, 47(3), 267-275. https://doi.org/10.1007/ s10144-005-0231-2
Derocher, A. (2013). Polar bears: A complete guide to their biology and behavior. Choice Reviews Online, 49(12), 49-6887. https://doi. org/10.5860/choice.49-6887

Derocher, A., Lunn, N., \& Stirling, I. (2004). Polar bears in a warming climate (Ursus maritimus). Integrative and Comparative Biology, 44(2), 163-176. https://doi.org/10.1093/icb/44.2.163

Derocher, A., \& Stirling, I. (1994). Age-specific reproductive performance of female polar bears (Ursus maritimus). Journal of Zoology, 234(4), 527-536.

Doligez, B., Clobert, J., Pettifor, R. A., Rowcliffe, M., Gustafsson, L., Perrins, C. M., \& McCleery, R. H. (2002). Costs of reproduction: Assessing responses to brood size manipulation on life-history and behavioural traits using multi-state capture-recapture models. Journal of Applied Statistics, 29(1-4), 407-423. https://doi. org/10.1080/02664760120108845

Eldegard, K., \& Sonerud, G. A. (2010). Experimental increase in food supply influences the outcome of within-family conflicts in Tengmalm's owl. Behavioral Ecology and Sociobiology, 64(5), 815-826. https://doi. org/10.1007/s00265-009-0898-z

Folio, D. M., Aars, J., Gimenez, O., Derocher, A. E., Wiig, Ø., \& Cubaynes, S. (2019). How many cubs can a mum nurse? Maternal age and size influence litter size in polar bears. Biology Letters, 15(5), 20190070. https://doi.org/10.1098/rsbl.2019.0070

Gimenez, O., Cam, E., \& Gaillard, J.-M. (2018). Individual heterogeneity and capture-recapture models: What, why and how? Oikos, 127(5), 664-686. https://doi.org/10.1111/oik.04532

Gimenez, O., Lebreton, J.-D., Gaillard, J.-M., Choquet, R., \& Pradel, R. (2012). Estimating demographic parameters using hidden process dynamic models. Theoretical Population Biology, 82, 307-316. https:// doi.org/10.1016/j.tpb.2012.02.001

Hansson, R., \& Thomassen, J. (1983). Behavior of polar bears with cubs in the denning area. In Bears: Their biology and management (pp. 246-254). Madison, Wisconsin: International Association for Bear Research and Management.

Hunter, C. M., Caswell, H., Runge, M. C., Regehr, E. V., Amstrup, S. C., \& Stirling, I. (2010). Climate change threatens polar bear populations: A stochastic demographic analysis. Ecology, 91(10), 2883-2897. https://doi.org/10.1890/09-1641.1

Kölliker, M., Kilner, R. M., \& Hinde, C. A. (2013). Parent-offspring conflict. In The evolution of parental care. Oxford: Oxford University Press.

Kramer, K. L. (2005). Children's help and the pace of reproduction: Cooperative breeding in humans. Evolutionary Anthropology: Issues, News, and Reviews, 14(6), 224-237. https://doi.org/10.1002/ evan.20082

Lagrange, P., Gimenez, O., Doligez, B., Pradel, R., Garant, D., Pelletier, F., \& Bélisle, M. (2017). Assessment of individual and conspecific reproductive success as determinants of breeding dispersal of female tree swallows: A capture-recapture approach. Ecology and Evolution, 7(18), 7334-7346. https://doi.org/10.1002/ece3.3241

Laidre, K. L., Atkinson, S., Regehr, E. V., Stern, H. L., Born, E. W., Wiig, $\varnothing$., Lunn, N. J., \& Dyck, M. (2020). Interrelated ecological impacts of climate change on an apex predator. Ecological Applications, 30(4), e02071. https://doi.org/10.1002/eap.2071

Lebreton, J. D., Nichols, J. D., Barker, R. J., Pradel, R., \& Spendelow, J. A. (2009). Chapter 3 modeling individual animal histories with multistate capture-recapture models. Advances in Ecological Research, 41, 87-173.

Lee, P. C., \& Moss, C. J. (1986). Early maternal investment in male and female African elephant calves. Behavioral Ecology and Sociobiology, 18(5), 353-361. https://doi.org/10.1007/BF00299666

Lee, R. (2008). Sociality, selection, and survival: Simulated evolution of mortality with intergenerational transfers and food sharing. Proceedings of the National Academy of Sciences of the United States of America, 105(20), 7124-7128. 
Lunn, N. J., Servanty, S., Regehr, E. V., Converse, S. J., Richardson, E., \& Stirling, I. (2016). Demography of an apex predator at the edge of its range: impacts of changing sea ice on polar bears in Hudson Bay. Ecological Applications, 26(5), 1302-1320.

Mauritzen, M., Derocher, A. E., Wiig, Ø., Belikov, S. E., Boltunov, A. N., Hansen, E., \& Garner, G. W. (2002). Using satellite telemetry to define spatial population structure in polar bears in the Norwegian and western Russian Arctic. Journal of Applied Ecology, 39(1), 79-90. https://doi.org/10.1046/j.1365-2664.2002.00690.x

McCarthy, M. A., \& Masters, P. (2005). Profiting from prior information in Bayesian analyses of ecological data. Journal of Applied Ecology, 42(6), 1012-1019. https://doi.org/10.1111/j.1365-2664.2005.01101.x

Pavard, S., \& Branger, F. (2012). Effect of maternal and grandmaternal care on population dynamics and human life-history evolution: A matrix projection model. Theoretical Population Biology, 82(4), 364-376. https://doi.org/10.1016/j.tpb.2012.01.007

Plummer, M., Stukalov, A., Denwood, M., \& Plummer, M. M. (2016). Package 'rjags'.

Pollock, K. H. (2002). The use of auxiliary variables in capture-recapture modelling: An overview. Journal of Applied Statistics, 29(1-4), 85-102. https://doi.org/10.1080/02664760120108430

Pradel, R. (2005). Multievent: An extension of multistate capturerecapture models to uncertain states. Biometrics, 61, 442-447. https://doi.org/10.1111/j.1541-0420.2005.00318.x

Pradel, R., \& Sanz-Aguilar, A. (2012). Modeling Trap-Awareness and related phenomena in capture-recapture studies. PLoS One, 7(3), e32666. https://doi.org/10.1371/journal.pone.0032666

Ramsay, M. A., \& Stirling, I. (1988). Reproductive biology and ecology of female polar bears in western Hudson Bay. Naturaliste Canadien, 109(4), 941-946.

Regehr, E. V., Hostetter, N. J., Wilson, R. R., Rode, K. D., Martin, M. S., \& Converse, S. J. (2018). Integrated population modeling provides the first empirical estimates of vital rates and abundance for polar bears in the Chukchi Sea. Scientific Reports, 8(1), 1-12. https://doi. org/10.1038/s41598-018-34824-7

Regehr, E. V., Laidre, K. L., Resit Akcakaya, H., Amstrup, S. C., Atwood, T. C., Lunn, N. J., \& Wiig, Ø. (2016). Conservation status of polar bears (Ursus maritimus) in relation to projected sea-ice declines. Biology Letters, 12(12), 20160556.

Royle, N., Smiseth, P., \& Kölliker, M. (2012). The evolution of parental care. Oxford: Oxford University Press.

Shenk, M. K., \& Scelza, B. A. (2012). Paternal investment and statusrelated child outcomes: Timing of father's death affects offspring success. Journal of Biosocial Science, 44(5), 549-569. https://doi. org/10.1017/S0021932012000053

Stearns, S. C. (1992). The evolution of life histories. Oxford University Press.
Stirling, I., \& Derocher, A. E. (2012). Effects of climate warming on polar bears: A review of the evidence. Global Change Biology, 18(9), 26942706. https://doi.org/10.1111/j.1365-2486.2012.02753.x

Stirling, I., Spencer, C., \& Andriashek, D. (1989). Immobilization of polar bears (Ursus maritimes) with Telazol in the Canadian Arctic. Journal of Wildlife Diseases, 25(2), 159-168.

Trivers, R. L. (1972). Parental investment and sexual selection. In B. G. Campbell (Ed.), Sexual selection and the descent of man, 1871-1971 (pp. 136-179). Aldine.

Van Noordwijk, M. A. (2012). From maternal investment to lifetime maternal care. In Evolution of primate societies (pp. 321-342). Chicago, Illinois: University of Chicago Press.

Vergara, P., Fargallo, J. A., \& Martínez-Padilla, J. (2010). Reaching independence: Food supply, parent quality, and offspring phenotypic characters in kestrels. Behavioral Ecology, 21(3), 507-512. https://doi. org/10.1093/beheco/arq011

Wich, S., Utami-Atmoko, S., Setia, T. M., Rijksen, H. D., Schürmann, C., Van Hooff, J. A. R. A., \& van Schaik, C. P. (2004). Life history of wild Sumatran orangutans (Pongo abelii). Journal of Human Evolution, 47(6), 385-398. https://doi.org/10.1016/j.jhevol.2004.08.006

Wiig, Ø. (1998). Survival and reproductive rates for polar bears at Svalbard. Ursus, 10, 25-32.

Williams, G. C. (1966). Natural selection, the costs of reproduction, and a refinement of Lack's principle. American Naturalist, 100, 687-690. https://doi.org/10.1086/282461

Yoccoz, N. G., Erikstad, K. E., Bustnes, J. O., Hanssen, S. A., \& Tveraa, T. (2002). Costs of reproduction in common eiders (Somateria mollissima): An assessment of relationships between reproductive effort and future survival and reproduction based on observational and experimental studies. Journal of Applied Statistics, 29(1-4), 57-64. https://doi.org/10.1080/02664760120108458

\section{SUPPORTING INFORMATION}

Additional supporting information may be found online in the Supporting Information section.

How to cite this article: Cubaynes S, Aars J, Yoccoz NG, et al. Modeling the demography of species providing extended parental care: A capture-recapture multievent model with a case study on polar bears (Ursus maritimus). Ecol Evol. 2021;11:3380-3392. https://doi.org/10.1002/ece3.7296 